\title{
Informação digital no ensino presencial e no ensino a distância
}

\author{
Marco Gonzalez \\ Mestre em Ciência da Computação pela PUCRS (Porto Alegre, RS, \\ Brasil). Especialista em Informática Empresarial e Análise de \\ Sistemas. Doutorando em Informática pelo PPGCC da PUCRS. \\ Professor da Faculdade de Informática da PUCRS. Pesquisador do \\ Projeto Campus Global na Faculdade de Informática da PUCRS. \\ gonzalez@inf.pucrs.br

\section{Omer Pohlmann Filho \\ Administrador, especialista em análise de sistemas e mestre em ciência da computação pela PUCRS (Porto Alegre, RS, Brasil). Professor da Faculdade de Informática da PUCRS. Pesquisador do Projeto Campus Global na Faculdade de Informática da PUCRS. Coordenador Executivo do Inmetro-RS. \\ omer@inf.pucrs.br}

\section{Karen Selbach Borges}

Bacharel em informática e mestre em ciência da computação pela PUCRS (Porto Alegre, RS, Brasil). Pesquisadora do Projeto Campus Global na Faculdade de Informática da PUCRS.

kborges@inf.pucrs.br

\section{Resumo}

Neste artigo, discutem-se o papel da informação digital e sua importância tanto para as universidades tradicionais quanto para as que adotam o paradigma de ensino a distância. Além disso, descreve-se a infra-estrutura básica necessária para a produção e disponibilização de acervo digital, destacando-se a criação de um Núcleo de Construção e Manutenção de Acervo Digital e de um Núcleo de Criação de Material Didático. Analisam-se também as diferenças relacionadas à disponibilização e pagamento de direitos autorais de documentos digitais disponibilizados em ambientes públicos ou restritos. Finalmente, apresentam-se as experiências dos autores no gerenciamento da informação digital disponibilizada aos alunos do ensino presencial.

Palavras-chaves

Ensino a distância; Informação digital; Bibliotecas digitais.

\section{Digital information on traditional class and distance learning}

\begin{abstract}
This paper discusses the role of digital information and its importance for both the traditional universities and the ones which follow the paradigm of distance education. It also describes the basic infrastructure needed for production and availability of the digital holdings, pointing out the establishment of a Nucleus of Construction and Maintenance of the Digital Holdings as well as a Nucleus of Generation of Didactic Material. It also analyzes the differences related to the availability and payment of copyright of digital documents available in public and private environments. Finally, some authors experiences are presented as regards management of digital information available for classroom students.
\end{abstract}

\section{Keywords}

Distance learning; Digital information; Digital libraries; Distance education.

\section{INTRODUÇÃO}

Enquanto são discutidas questões oportunas e importantes relacionadas ao ensino a distância como a definição do papel do professor, a realização de aulas síncronas ou assíncronas, o uso da Internet, o uso de videoconferência e outras mais, ocorre a evolução lenta e gradual do uso da informação digital como recurso de apoio às atividades de ensino ${ }^{1,2,3}$. Essa evolução está inserida em outra mais abrangente: a que transformará (ou está transformando) o ensino presencial em ensino a distância.

Entretanto, pode-se argumentar que essas duas modalidades de ensino sempre continuarão existindo. Neste caso, a evolução que se observa tão-somente comprova a importância da informação no ensino em geral, e o que se verifica é um processo crescente de informatização em termos de produção e disponibilização da informação.

Abordando estes fatos, serão analisados requisitos e propostos mecanismos para que a evolução em curso aconteça com sucesso e, ainda, serão relatadas experiências dos autores com a informação digital como apoio ao ensino presencial.

Apresentam-se aqui as pesquisas realizadas no Projeto Campus Global da PUCRS e a experiência adquirida no desenvolvimento de disciplinas na Faculdade de Informática da mesma universidade, com a utilização intensiva de planos de aula, avisos, publicações de graus, trabalhos, exercícios e material bibliográfico em forma de hipertextos. Também serão abordadas formas de utilização de bibliotecas digitais como apoio a este trabalho.

\section{O PAPEL DA INFORMAÇÃO DIGITAL NO ENSINO}

É pratica normal e correta fornecer, para cada disciplina, uma extensa lista bibliográfica, que deve ser de fácil acesso no mercado ou na maioria das bibliotecas públicas ${ }^{4}$. Entende-se também como de fundamental importância o papel da biblioteca da própria instituição de ensino. Porém, indivíduos residindo em locais pouco desenvolvidos, com bibliotecas e livrarias precárias ou mesmo inexistentes não têm acesso a uma grande parcela do material bibliográfico necessário para o correto desenvolvimento das disciplinas. 
Como forma de suprir esta carência, além do esforço dos educadores para desenvolver material didático a ser disponibilizado aos alunos, as novas tecnologias de informação e comunicação em rede mundial de computadores tornam possível a disponibilização do acervo de bibliotecas digitais e virtuais. A utilização destas bibliotecas expande os horizontes do ensino e da pesquisa, tornando praticamente ilimitada a liberdade dos educadores para indicar material bibliográfico, sem a preocupação com conceitos como lugar e quantidade disponível. Porém, cabe lembrar que a simples utilização da biblioteca digital para disponibilização de material bibliográfico não garante a qualidade da informação passada do professor ao aluno.

Mesmo assim, é fundamental o aproveitamento do potencial da informação digital tanto no ensino presencial como no ensino a distância. Mediante a utilização de documentos não estáticos, com âncoras para novas informações e com recursos naturais de navegação - os hipertextos -, pode-se vir a obter um aumento da capacidade intelectual humana ${ }^{5}$.

É na disponibilização de hipertextos em bibliotecas digitais, na sua utilização no planejamento do ensino, na confecção do material básico das disciplinas e na administração de aulas, que se concentra o objetivo deste trabalho. Tanto em regime presencial como a distância.

\section{Infra-estrutura para informação digital}

Tanto em universidades que se dedicam a trabalhar com ensino a distância como presencial, é fundamental a preocupação com a busca de soluções que viabilizem a construção de uma estrutura básica que apóie sob todos os aspectos a geração, manutenção e disponibilização da informação, principalmente no formato digital.

De acordo com as pesquisas desenvolvidas no Projeto Campus Global, constatou-se que uma universidade deve manter quatro tipos básicos de atividades: administração, pesquisa, educação e convivência acadêmica, que necessitam do suporte tecnológico, metodológico e de informação, conforme pode ser visto na figura 1 .

Dentro da universidade, o órgão encarregado de prover o suporte de informação é a biblioteca. Quando se fala em informação digital é preciso falar também de biblioteca digital. Neste contexto, entende-se a biblioteca como algo bem mais amplo do que um depositório de livros, revistas etc. Já uma biblioteca digital se caracteriza por manter um conjunto mais diversificado de informações, que abrange
FIGURA 1

Atividades e suportes na universidade virtual

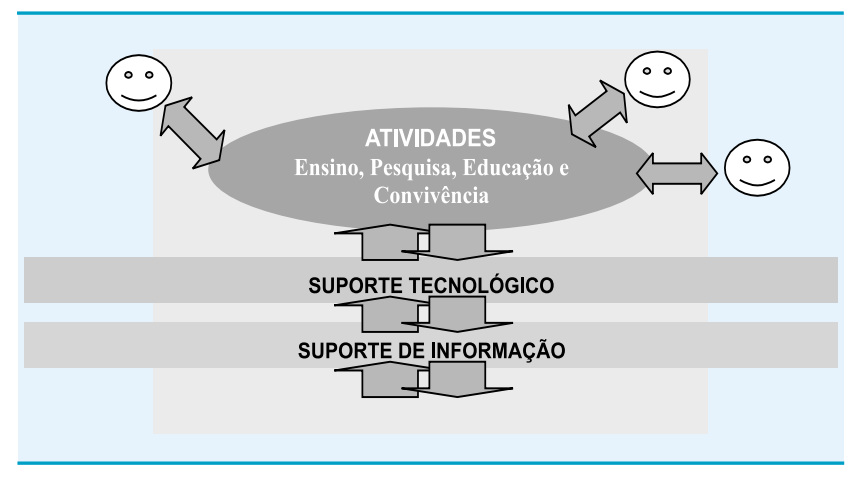

desde as bibliografias básicas das disciplinas até o material de aula dos professores, passando por fotos, vídeos, sons etc.

Para a criação de uma biblioteca digital, é necessária a construção de uma cultura que vai desde a definição de uma sistemática de digitalização de documentos ${ }^{6}$, até o modelo completo de uma biblioteca digital. Isto passa necessariamente pela submissão e disponibilização de objetos digitais em um modelo que:

- contemple os aspectos legais, inclusive o pagamento dos direitos de autor e que viabilize tanto a criação de acervo digital próprio como a criação de links para outra bibliotecas digitais ${ }^{7}$;

- contemple mecanismos de pesquisa necessariamente eficientes, haja vista a quantidade e diversidade de documentos digitais existentes ${ }^{8}$;

- mantenha um controle seguro de acesso e registro de acesso';

- contemple uma sistemática de empréstimo de documentos digitais que possa ser utilizada pelo universo de usuários da biblioteca e que permita maior facilidade para a negociação dos direitos autorais ${ }^{10}$.

\section{Biblioteca digital}

Transcendendo os conceitos tradicionais, as bibliotecas estão deixando de ser um tranqüilo depósito de livros para se tornarem o ponto focal de pesquisa variada, acessada a qualquer hora por usuários de vários lugares do mundo ${ }^{5}$.

De acordo com Cunha ${ }^{11}$, as bibliotecas tradicionais estão em um momento de transição: a organização totalmente dependente do material impresso está passando para outro 
contexto, onde tudo, ou quase tudo, será armazenado sob o formato digital - são as bibliotecas digitais. A seguir, são citados alguns conceitos e classificações de bibliotecas utilizados:

- Bibliotecas Polimídias: são similares às tradicionais, porém, convivendo com livros, estão vídeos, fitas, CDROMs, microfilmes etc. ${ }^{12}$;

- Bibliotecas Eletrônicas: pressupõem a existência de um acervo físico e utilizam recursos computacionais de uma forma ampla para armazenamento e recuperação de registros, construção e disponibilização de índices eletrônicos, busca e recuperação de textos completos em outras bibliotecas digitais ${ }^{12}$;

- Bibliotecas Digitais: diferem das demais porque suas informações existem somente de forma digital (em disquetes, winchester, CDs etc.), não contendo livros na forma convencional. Dispõem de todos os recursos de uma biblioteca eletrônica, oferecendo pesquisa e visualização dos documentos (full text, vídeo etc.), tanto local como remotamente por meio de redes de computadores ${ }^{13}$;

- Biblioteca Virtual: este termo remete a dois conceitos principais. Um, segundo Marchiori ${ }^{13}$, está ligado ao conceito de realidade virtual e, portanto, utiliza recursos de software que simulam um ambiente de biblioteca na tela do computador, criando imagens em três dimensões que possibilitam entrar e circular pelas prateleiras de uma biblioteca virtual, acessar e ler livros, possuindo, assim, a característica de imersão. Por outro lado, Cianconi* conceitua biblioteca virtual como uma relação de sites organizados segundo um critério temático, como se fosse um catálogo, não estando vinculada a nenhuma biblioteca do mundo real.

Cabe aqui salientar que essa última autora relaciona biblioteca digital com biblioteca virtual no sentido de que a primeira deve prever a organização de uma biblioteca virtual. Ainda, segundo a mesma, a diferença entre biblioteca digital e biblioteca virtual é que a primeira sempre está vinculada a uma instituição, e seus links de hipertexto apontam para acervos existentes. No contexto do projeto Campus Global, trabalha-se com o conceito de biblioteca virtual segundo Cianconi.

\footnotetext{
* CIANCONI, R. Literatura (e Conceitos). Mensagem disponível na Internet via lista de discussão bib_virtual@buriti.ibict.br, ago. 1997.
}

\section{Informação digital pública ou restrita}

As pesquisas realizadas no Laboratório de Biblioteca Digital do Campus Global da PUCRS têm, em razão do alcance da disseminação da informação das bibliotecas digitais, apontado para a existência de dois ambientes de documentos (público e restrito) ${ }^{7}$, que devem ser tratados separadamente em função de suas características distintas:

- Ambiente Restrito - Os documentos deste ambiente devem ter controle de acesso com limitação do número de usuários por meio da sua identificação, havendo necessidade de se manter um cadastro de usuários. Cada usuário poderá ter direito de acesso a um, alguns ou todos os documentos. Dependendo do ambiente ou dos objetivos do acervo, poderiam existir, entre outros, ambientes restritos específicos, como, por exemplo, de uma instituição de ensino ou de uma empresa. $\mathrm{O}$ ambiente de ensino poderia ser uma universidade, ou, restringindo ainda mais, uma turma de uma disciplina. Neste último caso, teríamos documentos constituindo material de apoio às aulas que, em se tratando de ensino a distância, atenderiam à situação de ausência física do professor, ou, em caso contrário, simplesmente seriam uma fonte de informação complementar. Alunos e professores seriam cadastrados como usuários autorizados. No caso de uma empresa, o ambiente restrito ficaria caracterizado pelo conjunto de documentos (catálogos de equipamentos, apostilas de treinamento etc.) que teriam como usuários autorizados os próprios funcionários da empresa.

- Ambiente público - Os documentos deste ambiente não possuem limitação do número de usuários, sendo liberados a qualquer um que tenha acesso à interface do acervo. Como exemplo poderíamos ter bases de dados documentais de bibliotecas públicas ou o acervo público de uma entidade governamental. Também poderíamos considerar, como públicos, documentos como teses e dissertações de uma biblioteca universitária.

Uma biblioteca poderia trabalhar apenas em um destes ambientes ou em ambos, dependendo dos seus objetivos. Em termos de direito autoral, em um ou outro caso poderíamos ter documentos com cessão ou não de direitos autorais ${ }^{7}$. Por isso, o "ambiente público" (em que todos têm direito de acesso, ainda que, em alguns casos, seja exigido pagamento de direito autoral) não deve ser confundido com "domínio público" (em que todos têm direito de acesso sem qualquer tipo de remuneração de direito autoral). 
No ambiente de construção do modelo de Universidade Virtual, no qual se encaixa a biblioteca digital do Campus Global da PUCRS, verifica-se a necessidade de se trabalhar nos dois ambientes: restrito (apostilas de aula, artigos em construção, entre outros) e público (dissertações, artigos publicados etc.). Ambos, ainda, sem documentos que exijam remuneração de direito autoral.

A figura 2 apresenta as distinções que devem ser feitas em uma biblioteca digital, considerando-se os ambientes dos documentos digitais e o pagamento do direito autoral.

Não havendo pagamento de direito autoral, em ambiente restrito exige-se apenas o mecanismo de controle para garantir o acesso aos documentos digitais somente a usuários autorizados. Em ambiente público, há necessidade de gerenciamento da interface da biblioteca digital sem qualquer restrição ao acesso.

Havendo pagamento de direito autoral, em ambiente restrito, a situação é a mais complexa possível, gerando a necessidade de implementação de uma sistemática para controle de acesso, para empréstimo somente a usuários autorizados e para registro e elaboração de estatísticas de acesso que contemplem mecanismos para tratamento e remuneração dos direitos autorais. Em ambiente público, a complexidade diminui, restando apenas a necessidade do registro de acesso e da remuneração.

Cabe salientar que uma conclusão da equipe de pesquisa do Laboratório de Biblioteca Digital do Campus Global é que os mecanismos de controle e empréstimo não são pertinentes no ambiente público. Isto, pela própria característica do mesmo, que não pressupõe o controle de usuários autorizados. Como o mecanismo de empréstimo definido no modelo de Biblioteca Digital da PUCRS prevê o empréstimo apenas a usuários autorizados ${ }^{10}$, não deve estar contemplado neste ambiente.

Também as formas de negociação e remuneração dos detentores dos direitos autorais das obras digitais variam muito de um ambiente para outro, em função das características distintas de cada um. $\mathrm{O}$ ambiente público prevê a disponibilização de um universo muito grande de objetos a um público usuário também muito grande e heterogêneo. O software a ser utilizado neste ambiente em geral é muito caro, e devem ser contempladas leis e tratados internacionais. Isto leva naturalmente a uma maior dificuldade na negociação dos direitos autorais. Já no ambiente restrito, o material bibliográfico e de apoio a ser disponibilizado tem um público-alvo menor e mais homogêneo, permitindo um controle de acesso mais fácil.
FIGURA 2

Ambientes de disponibilização e pagamento de direito autoral

\begin{tabular}{lcc}
\hline Direito autoral & $\begin{array}{c}\text { Ambiente } \\
\text { restrito }\end{array}$ & $\begin{array}{c}\text { Ambiente } \\
\text { público }\end{array}$ \\
sem pagamento & controle & \\
com pagamento & $\begin{array}{c}\text { controle } \\
\text { empréstimo } \\
\text { registro } \\
\text { remuneração }\end{array}$ & $\begin{array}{c}\text { Registro } \\
\text { remuneração }\end{array}$ \\
\hline
\end{tabular}

O software a ser utilizado em geral é mais simples e barato, as leis a serem atendidas são locais, acarretando maior facilidade para negociação dos direitos autorais.

\section{Controle e registro de acesso}

A preservação de documentos digitais envolve integridade, quando são protegidos contra alterações autorizadas, mas indevidas, e segurança, quando são protegidos contra terceiros ${ }^{14}$. Os avanços da tecnologia da informação tornam a preservação dos dados cada vez mais complexa e difícil de projetar e otimizar. Em uma biblioteca digital, questões relacionadas com a segurança em termos de controle e registro de acessos ganham importância em razão do direito autoral. Estes avanços, que modificam profundamente as práticas sociais e profissionais relativas ao uso da informação, trazem questionamentos sobre os fundamentos ou as justificativas das reivindicações dos titulares de direitos ${ }^{15}$. De qualquer forma, o controle e o registro de acesso aos documentos são necessários e consistem a essência da interface usuário - acervo digital.

Segundo Davies ${ }^{16}$, os métodos usados para a identificação do usuário podem ser classificados em quatro categorias: (a) identificação mediante algo que o usuário conhece; (b) identificação mediante algo que o usuário possui; (c) identificação mediante uma característica do usuário; (d) identificação mediante resultado de uma ação involuntária do usuário. $\mathrm{O}$ uso de senha e de cartão de crédito são exemplos das categorias (a) e (b). As categorias (c) e (d) não são sempre diferenciadas uma da outra, mas, no caso da informática, teríamos como exemplo o uso do endereço $\mathrm{IP}^{1 *}$ da máquina do usuário.

\footnotetext{
$\overline{{ }^{*} \text { Endereço que identifica a máquina do usuário no contexto da Internet. }}$
} 
Segundo Gonçalves ${ }^{17}$, a proteção básica dos documentos na Web deve levar em conta: (a) o endereço IP ou a identificação da sub-rede ou do domínio usado; (b) o nome e a senha do usuário; (c) a utilização de criptografia de documentos. Segundo o mesmo autor, as informações sobre um usuário podem incluir: (a) o endereço IP de sua máquina; (b) o nome do servidor; (c) o momento do acesso (data e hora), (d) o nome do usuário, se conhecida sua identificação; (e) o endereço URL ${ }^{* 2}$ requisitado pelo usuário; (f) os argumentos submetidos via formulários, (g) o status da requisição do usuário; (h) o tamanho do documento transmitido.

O objetivo básico de uma biblioteca digital é tornar acessível ao computador do usuário a informação disponível, implicando, entre outras $\operatorname{coisas}^{18}$, a existência de:

- base de dados documentais;

- aplicativo de acesso a documentos digitais com gerenciamento e controle de acesso de usuários;

- acesso a outras bases documentais e/ou bibliográficas e/ou a bibliotecas virtuais temáticas.

A biblioteca digital da PUCRS, por meio de sua página principal na Internet (http:// www.cglobal.pucrs.br/bibdigital), possibilita acesso ao acervo digital e também às bibliotecas virtuais temáticas do Campus Global: ensino a distância, biblioteca digital e trabalho cooperativo.

O acervo digital do Campus Global da PUCRS está em fase inicial de construção ${ }^{19,6}$, possuindo uma base de dados documentais com as seguintes características:

- indexação interna com código do documento, identificação do arquivo digital, identificação da sua capa virtual e chave de busca;

- documentos digitais de ambiente restrito e público nos seguintes formatos: $\mathrm{PDF}^{* * 3}$ e HTML***4.

\footnotetext{
* Endereço que localiza um documento na Internet.

** Documentos construídos através do aplicativo AdobeAcrobat.

*** Documentos com acesso obtido diretamente por um browser Web.
}

FIGURA 3

Esquema do controle e registro de acesso (CARA) ao acervo digital do Campus Global da PUCRS

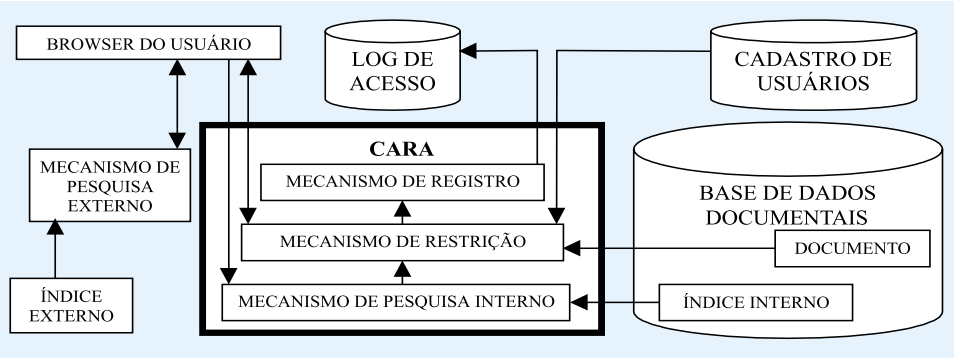

FIGURA 4

Esquema geral do controle de acesso ao acervo digital da PUCRS

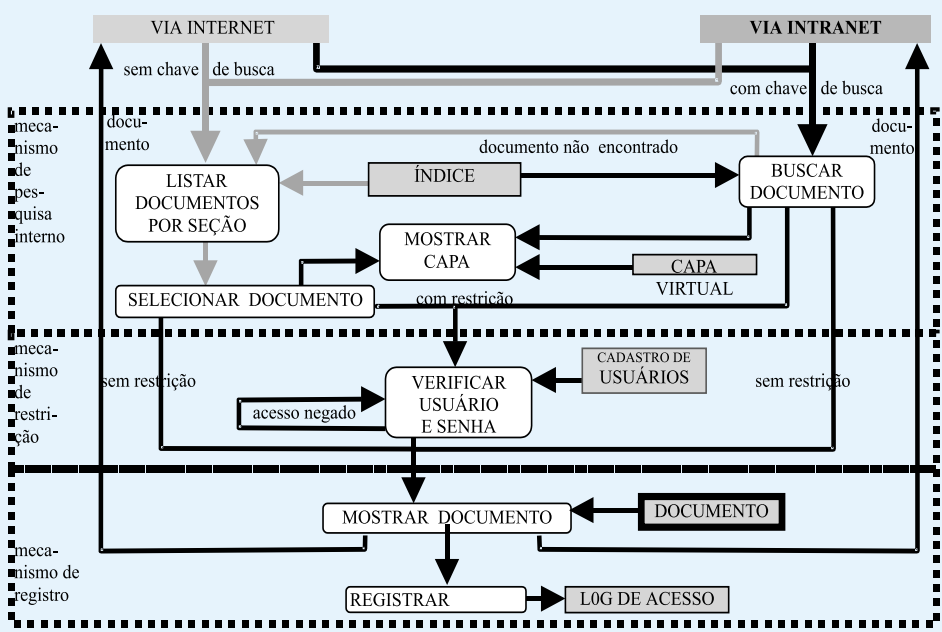

O acesso ao acervo digital da PUCRS é feito pela interface CARA (Controle de Acesso e Registro de Acesso) ${ }^{9}$, conforme esquema mostrado nas figuras 3 e 4 . Pode-se observar que pelo seu browser o usuário consegue interagir diretamente com os mecanismos de pesquisa internos e externos, ou com o mecanismo de restrição de acesso, quando já souber o endereço da obra a ser obtido o acesso.

O esquema geral do controle de acesso pode ser visto na figura 4. Em ambiente Internet ou Intranet, o usuário tem dois modos de acesso: (a) sem chave de busca (nesse caso é apresentada a listagem de documentos por seção para que o usuário possa fazer a seleção), ou (b) com chave de busca (nesse caso algum mecanismo de pesquisa externo possibilita a busca direta do documento).

A chave de busca de um documento é construída de forma a oferecer ao usuário informações iniciais suficientes para apoiar uma possível escolha. Isso é complementado pela apresentação da capa virtual do documento, se o usuário assim desejar, antes do processo de seleção. A próxima etapa, após a localização do documento, consiste na 
verificação de usuário e senha (em ambiente restrito), ou em mostrar o documento (em ambiente público).

No caso em que é solicitado ao usuário seu nome e sua senha para liberação de um documento restrito, um programa CGI $^{*}$ recebe esses dados, além do número de indicação do documento desejado. E6stando nome e senha corretos, verifica se existe direito de acesso. Se tudo estiver correto, o documento estará liberado para o usuário.

A apresentação do documento selecionado, obedecendo ao formato do arquivo, é feita então por meio do browser do usuário. O registro de acesso, antes disso, é feito por programa CGI, que guarda, no "log de acesso", as seguintes informações:

- data e hora do servidor;

- código do documento no acervo;

- nome do arquivo que contém o documento;

- nome do usuário, caso seja um documento de ambiente restrito;

- endereço IP do servidor remoto de onde o usuário faz a solicitação de acesso;

- nome do servidor remoto (se houver esta informação);

- identificação e o nome do usuário (se o servidor suportar processo de identificação e autenticação através de processos próprios de seu sistema operacional).

Com estas informações, são elaboradas estatísticas e relatórios de acesso ao acervo digital.

\section{O problema do direito autoral}

Para a criação de um acervo digital, há de se conciliarem a aquisição de obras digitais e o pagamento dos direitos autorais. O problema está na troca do paradigma adquirir versus disponibilizar. Nas bibliotecas tradicionais, o empréstimo de uma obra é proporcional ao número de exemplares adquiridos; já nas bibliotecas digitais, para disponibilizar, basta ter um exemplar digital. Isto causa profunda transformação na negociação dos direitos autorais, pois o objetivo dos autores e editores deixa de ser o de "vender um exemplar da obra" e passa a ser algo ainda passível de discussão, como a negociação de: (a) número de licenças da obra digital para empréstimo; (b) permissões de acesso ou a disponibilização mediante remuneração, como, por exemplo, aos alunos de uma determinada disciplina.

\footnotetext{
* Programa que faz a ligação, neste caso, entre uma página HTML e os dados armazenados no servidor
}

FIGURA 5

Exemplo de alocação de objetos digitais

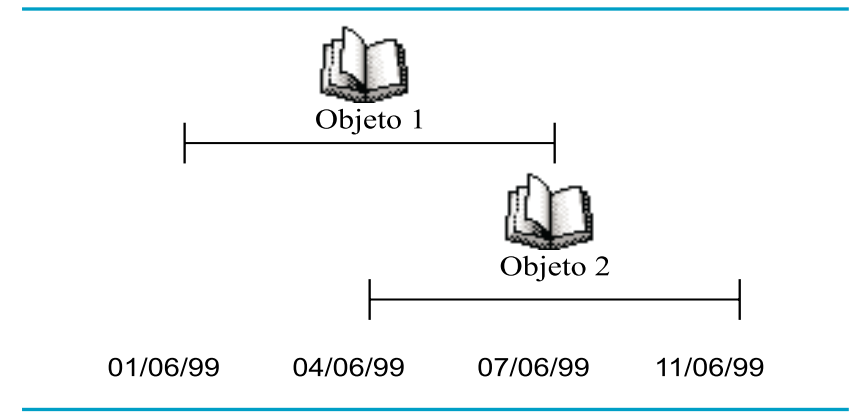

Também questões, como ler, copiar e imprimir, influem significativamente quando se trata de buscar soluções que contemplem o pagamento dos direitos do autor, visto que existe ainda muita relutância por parte destes em deixar disponível sua obra em um ambiente onde são muitas as facilidades para leitura, cópia e impressão. Oppenheim ${ }^{20}$ destaca a necessidade de elaboração de sistemas eletrônicos de gestão dos direitos autorais que permitam identificar ou sinalizar a obra protegida e controlar sua utilização. Segundo o autor, estes sistemas seriam constituídos a partir de mecanismos sólidos, confiáveis, econômicos e a prova de interferência que forneceriam aos editores as novas garantias de que necessitam para conceder mais facilmente as permissões para disponibilização de suas publicações.

Nesse sentido, está sendo desenvolvido, para a Biblioteca Digital da PUCRS, um sistema que gerencia empréstimos e devoluções de objetos digitais (Sistema de Empréstimo de Objetos Digitais - SEOD) ${ }^{10}$. Este sitema contempla um ambiente para empréstimo de objetos digitais muito semelhante ao que existe hoje em um ambiente de biblioteca tradicional. Prevê a aquisição de licenças de uso dos objetos digitais, a exemplo da sistemática tradicional de compra de exemplares físicos de obras. Prevê também o controle de cotas de usuários e o empréstimo seguro de, no máximo, o número de licenças adquiridas de cada objeto.

A devolução dos objetos digitais ocorre de forma espontânea ou compulsória. O primeiro caso ocorre nos casos em que o usuário esteja com sua cota de alocação preenchida e deseje, então, devolver algum livro para poder retirar novos exemplares.

A devolução compulsória ocorre quando o objeto e seu registro são eliminados do sistema automaticamente, por estarem com seus prazos de utilização vencidos. Suponhamos que o usuário tenha em seu poder dois objetos, com prazos de validade distribuídos ao longo do tempo conforme a figura 5 . 
Se o sistema do usuário for utilizado no dia 05/06/99, os prazos de utilização dos livros passarão para a situação da figura 6.

Ainda, se o sistema for utilizado no dia 08/06/99, o objeto 1 é eliminado do sistema, uma vez que o seu prazo de utilização era anterior à data em que o sistema foi iniciado.

Em paralelo, diariamente, o Sistema Bibliotecário realiza uma verificação de quais livros podem ser liberados para novo empréstimo. Dessa forma, o número de licenças de uso do livro é acrescida em uma unidade, enquanto a cota do usuário é decrescida em uma unidade.

Além desse processo e controle de datas, o SEOD faz uso de outros mecanismos de segurança, tais como:

- Criptografia de chave dupla - Neste tipo de sistema, cada pessoa tem duas chaves: uma chave pública e uma chave privada. As mensagens criptografadas com uma das chaves do par só podem ser decriptografadas com a outra chave correspondente; portanto, qualquer mensagem criptografada com a chave pública só pode ser decriptografada pela chave privada. Visa a proteger os dados contra alterações e uso não autorizados.

- Calculo de hash - Ao enviar o pacote de dados, o Sistema Bibliotecário gera um número a partir do conteúdo do pacote. Ao recebê-lo, o Sistema Cliente calcula novamente este número. Se houver diferença entre o número informado pelo Sistema Bibliotecário e aquele calculado pelo Sistema Cliente, verifica-se a violação da integridade dos dados transmitidos.

- Autenticação de usuário - Para iniciar o uso do Sistema Cliente em modo on-line, é necessário que o usuário identifique-se por meio de um código (login) e uma senha. Com isso, é possível restringir o acesso ao Sistema Bibliotecário somente a usuários cadastrados e autorizados.

Este sistema, que faz parte do modelo completo de biblioteca digital que está sendo implantado na PUCRS, deve ajudar principalmente na primeira etapa do processo de criação do acervo digital. Isto porque a implantação de cursos ou turmas a distância torna imprescindível a tarefa de disponibilizar o material bibliográfico referenciado. Ocorre que este processo vem se mostrando excessivamente lento em função da falta de soluções que permitam a agilização do mesmo. Com o SEOD, entendese que as negociações para "aquisição" de licenças para empréstimo de objetos digitais possam avançar mais rapidamente devido às semelhanças com as atuais formas
FIGURA 6

\section{Exemplo de atualização de prazos de utilização de um} objeto digital

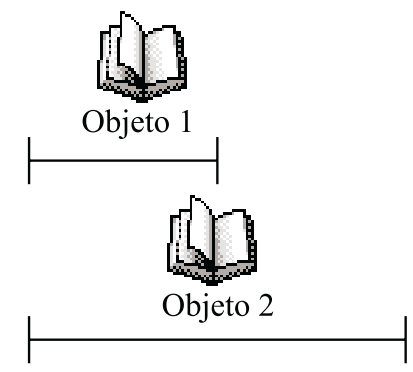

de negociação. Por exemplo, entende-se como bastante natural atribuir o valor de uma licença de empréstimo igual ao de um exemplar físico de um livro. Com isto, em vez de se comprarem cinco exemplares de um livro, que garante à editora que no máximo cinco exemplares serão emprestados, será possível adquirir cinco licenças de uso pelo mesmo preço, pois o SEOD garantirá que serão realizados no máximo cinco empréstimos simultâneos.

Embora este sistema possibilite acesso ao sistema bibliotecário e ao seu acervo somente a usuários cadastrados, também abre a possibilidade de as bibliotecas oferecerem serviços como provedoras de informações mediante a cobrança de taxas de acesso. Se por alguns isto pode ser visto como "manipulação da informação" ou "desvio do papel educacional da biblioteca", em contrapartida, permite a captação de recursos para a ampliação e manutenção do acervo, contratação de mãode-obra especializada e atualização tecnológica.

Além disso, tal sistema viabiliza a negociação para aquisição de livros em formato digital por parte das bibliotecas que desejam iniciar o processo migratório para o novo modelo. Isso, até então, não era possível devido ao receio de editoras e autores de que suas obras fossem distribuídas sem qualquer tipo de controle e, conseqüentemente, sem meios de arrecadação por seu uso.

Outro ponto a favor do SEOD é o fato de que ele não impede que o usuário retire um número de livros que ultrapasse sua cota de empréstimos. Em uma biblioteca tradicional, tal solicitação seria imediatamente negada. Neste caso, o SEOD passa a atuar como um gerenciador de pay-per-view, debitando da conta do usuário o valor pelo empréstimo do livro ${ }^{21}$. 


\section{Núcleo de criação de material didático digital}

Para suporte à criação de uma biblioteca digital, prevê-se a necessidade de criação de um núcleo de construção e manutenção do acervo digital responsável pelo fluxo de trabalho que vai da submissão à disponibilização de um documento ${ }^{22}$.

O elemento básico para aprendizagem em regime de ensino a distância continua a ser constituído por textos escritos ${ }^{4}$. Neste regime, o texto correspondente tem de sofrer um tratamento específico para adaptá-lo à situação de ausência física do professor. Com base nisto, há um outro projeto em estudo no laboratório de bibliotecas digitais da PUCRS, que envolve a criação de um núcleo de apoio à elaboração de material didático digital. Este núcleo poderá trabalhar de duas formas distintas: a primeira, com ênfase na pesquisa e repasse ao corpo docente da instituição de novas e modernas técnicas e metodologias para criação de acervo digital, ou seja, trabalhar na capacitação do corpo docente; outra, que é empregada com sucesso na PUC-RJ, no sistema Maxwel, que trabalha também na criação de uma biblioteca digital para aquela universidade, prevê a elaboração, pelo pessoal do núcleo, dos documentos digitais para serem incluídos no acervo.

A idéia de trabalhar na produção da informação digital com estas duas linhas distintas deverá promover rápido aumento no volume do acervo digital de apoio, pois atenderá tanto a professores que se propõem a elaborar seu próprio material e para tanto poderão contar com o repasse de modernas técnicas e metodologias que lhes permitam gerar material de qualidadade, como atenderá também aos professores que querem utilizar este tipo de material de apoio, mas não querem eles próprios criá-los, podendo contar com uma equipe especializada para isto.

Entende-se que a implantação de um núcleo de criação de material didático digital levará ao encontro do que prega a Uned ${ }^{23}$, que afirma não ser imprescindível a relação direta professor/aluno. É possível ao aluno, sozinho, aprender determinados conteúdos, desde que utilize uma tecnologia adequada e disponha de instrumentos pedagógicos apropriados, que possam ser sintetizados em materiais didáticos, criando condições para agilizar a implantação de programas de ensino a distância. Estes programas aplicados tanto de maneira complementar à presencial, como de forma pura, ou seja, programas que trabalhem a educação sem a modalidade presencial, podem auxiliar na introdução de novos instrumentos tecnológicos para comunicação e acompanhamento dos alunos. Os materiais de apoio elaborados poderão
FIGURA 7

\section{Esquema de estrutura de documentos}

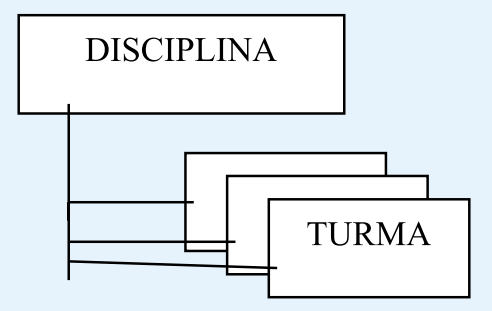

igualmente ser de grande utilidade na educação presencial. Como exemplo pode-se citar o caso da Universidade Nacional Autônoma de Honduras, onde o setor de educação a distância nutre toda a universidade com materiais de apoio para cursos presenciais.

\section{EXPERIÊNCIAS DOS AUTORES}

Conforme Aguirre ${ }^{24}$, um mestre deve prever as interações educativas e prover os recursos para que se dêem dentro do espaço para a aprendizagem. Isto inclui as referências mínimas que o aluno deve estudar e também uma base de documentos relacionados às tarefas individuais e grupais que cada aluno deve realizar, as discussões, comentários, questionamentos etc., bem como uma base de documentos com os perfis pessoais para permitir maior entrosamento entre os participantes.

Esta afirmativa conduziu a uma busca para idealizar uma base de documentos para atender a estas exigências. Neste sentido, conceberam-se dois modelos de estruturação de documentos, visando a contemplar as informações necessárias para o apoio e a complementação tanto de aulas virtuais como presenciais. A seguir, apresentamos esses dois modelos: (a) centralizado e (b) personalizado.

O primeiro modelo centraliza todas as informações básicas de uma disciplina em sua página inicial. Desta página, o usuário pode navegar buscando os dados que deseja em páginas vinculadas à inicial através de links. Na página inicial, podem ser encontradas informações gerais a respeito da disciplina, como pré-requisitos, programa, sistemática de avaliação e, também, a bibliografia utilizada, sendo remetida, quando for o caso, a documentos do acervo digital. As páginas seguintes incluem dados específicos sobre as turmas da disciplina. Estas informações são gerenciadas pelos respectivos professores, incluindo plano de aula, exercícios, enunciado de trabalhos e outros 
materiais de apoio às aulas, além da publicação de graus. Um esquema desta base de documentos pode ser visto na figura 7 (p. 108).

É importante ressaltar que cada uma destas bases contém hiperdocumentos com links para outros hiperdocumentos, inclusive bibliografia, centralizados e gerenciados como um site Web, facilitando a consulta por parte do aluno. A página com a bibliografia da disciplina remete diretamente ao acervo digital da biblioteca, quando o documento estiver lá armazenado.

Na figura 8, pode ser observado o plano de aula de uma disciplina com links para o material de que o aluno necessita para acompanhar cada uma das aulas. Também aqui temos um exemplo de como organizar a informação digital e, ao mesmo tempo, facilitar seu acesso.

O segundo modelo de estruturação é mais personalizado e exige mais do professor em termos de conhecimento de linguagema HTML e outros recursos dirigidos à Web. De qualquer forma, como o modelo anterior, utiliza o plano de aula como documento centralizador de links para informações úteis ao aluno, embora outros caminhos também estejam presentes.

São sugeridos, como links úteis, horário do professor, materiais diversos de apoio (biblioteca), programa da disciplina (que pode remeter a um único documento armazenado para todas as turmas da disciplina), o plano de aula (que centraliza e organiza o conjunto de informações, tornando o acesso mais intuitivo ao aluno, como pode ser visto na figura 9), notas do aluno, trabalhos e exercícios (enunciados e respostas - liberadas quando for conveniente). Tudo isto pode ficar sob restrição de senha ou não, dependendo da decisão do professor.

Pela experiência dos autores, utilizando os dois modelos de disponibilização de informação digital para disciplinas apresentados anteriormente, a comodidade e a praticidade para o professor e para o aluno, revertem-se em eficiência para o processo de aprendizado. Esta sistemática proposta organiza o acompanhamento da disciplina por parte do aluno. Sempre há uma referência na qual o aluno pode se apoiar para prever o andamento do trabalho do professor. Esta referência centraliza-se no plano de aula. Por outro lado, há exigência de organização por parte do professor para conseguir disponibilizar tal conjunto de informações digitais.

\section{FIGURA 8}

Plano de aula no modelo centralizado

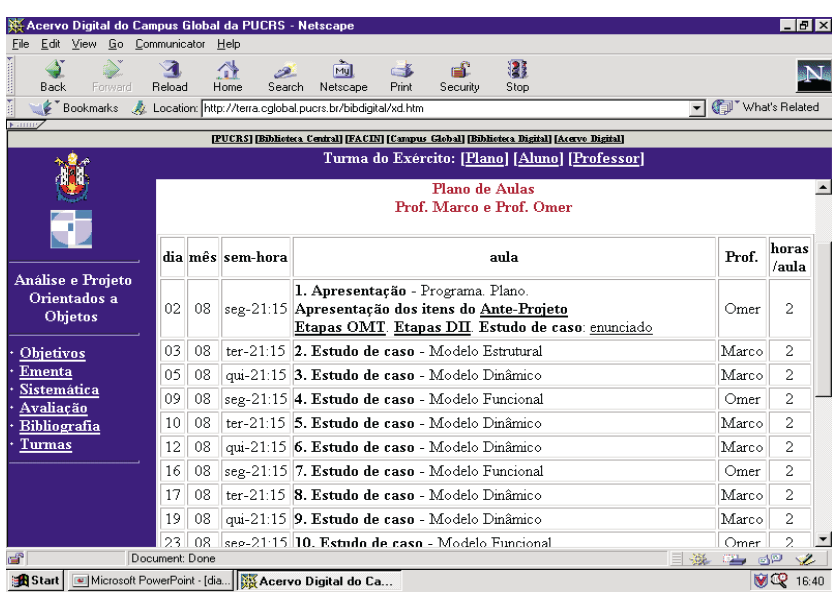

FIGURA 9

Plano de aula no modelo personalizado

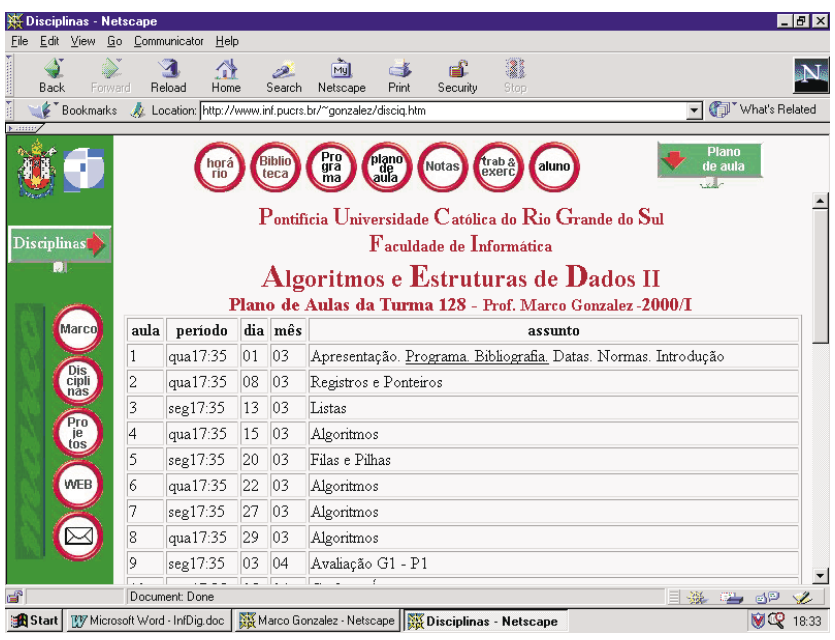

Esta concepção está prevista para ambientes restritos, ou seja, restrita aos alunos de determinadas turmas e/ou disciplinas. Isto permite aos professores razoável grau de privacidade, visto que os mesmos poderão determinar o universo de usuáros do material preparado. Isto no caso de o professor querer resguardar o seu direito de autor. Caso resolva abrir mão do mesmo e disponibilizar o material das disciplinas em um ambiente público, poderá fazê-lo sem nenhum problema. A maior vantagem desta concepção que prevê o trabalho em ambiente restrito é a facilidade de negociação dos direitos do autor. Pode-se, por exemplo, negociar com autores e editores o pagamento para utilização destes documentos a cada edição da disciplina (isto inclui bibliografia básica e material de aula). Pode-se também negociar o pagamento baseado no universo de usuários e, ainda, outras formas de negociação 
que somente são possíveis e facilitadas quando se trabalha em ambiente restrito?

\section{CONCLUSÕES}

Em uma universidade virtual ou mesmo em uma universidade tradicional com algum grau de informatização, é fundamental a preocupação com uma infra-estrutura básica que apóie em todos os aspectos a geração, manutenção e disponibilização da informação, inclusive e principalmente no formato digital.

Para o sucesso do que denominamos Núcleo de Construção e Manutenção de Acervo Digital, devem ser dominadas técnicas para:

- procedimentos da submissão de documentos digitais, considerando aspectos de workflow com especificações técnicas e legais;

- digitalização e formatação de documentos;

- implementação de interface do usuário com o acervo digital, com inclusão de recursos para recuperação de informação;

- controle e registro de acesso ao acervo;

- sistemática de empréstimo de documentos digitais;

- tratamento de direito autoral, cuja preocupação deve estar presente nas sistemáticas de controle e de registro de acesso, nos contratos elaborados durante a submissão de documentos e, fundamentalmente, quando tratamos de empréstimo digital.

Por outro lado, temos de pensar no suporte a ser dado ao professor para preparar suas aulas no sentido de organizar a informação digital a ser usada pelo aluno. $O$ tratamento de direito autoral ainda é um desafio e, conforme Cunha ${ }^{11}$, monografias sob a forma digital e em texto completo ainda são escassas e/ou caras. Neste sentido, salientamos a importância da formação do que denominamos Núcleo de Apoio e Criação de Material Didático Digital. O objetivo é apoiar o professor de diferentes maneiras, (a) desde a elaboração de páginas HTML, a partir de conteúdos desenvolvidos pelo professor, ou implementação de programas CGI para publicação de graus; (b) até a simples orientação quanto à composição ou disponibilicação (via Internet) do material didático. Esta abordagem passaria inclusive pela implantação de cursos para capacitação de professores para tarefas de elaboração de planos de aula, textos, enunciados de exercícios, publicação de graus, links com o acervo digital, para viabilizar o uso da bibliografia da disciplina, além de outros serviços e recursos específicos.

Todas estas abordagens baseiam-se na importância fundamental da informação no ensino. Esta é uma verdade incontestável tanto para a universidade presencial quanto para a universidade virtual. $O$ crescimento da utilização e, em conseqüência, da importância da informação digital, na realidade, já faz parte de um processo gradual que transforma lentamente todo ou parte do ensino tradicional em algo diferente, em razão da evolução das tecnologias da comunicação e da computação. Entretanto, para chegar lá, será necessário, antes, dominar adequadamente as técnicas para produzir e distribuir a informação digital. Isto significa que a evolução do ensino passa pela produção de material didático digital e pela implementação dos recursos de uma biblioteca digital. Este não deve ser um esforço secundário, mas paralelo e simultâneo com aquele que tenta compreender e apoiar o comportamento do professor e do aluno, tendo como foco a aula virtual, na construção da Universidade do futuro.

\section{REFERÊNCIAS BIBLIOGRÁFICAS}

1. MAGDALENA, B. C.; MESSA, M. R. P. Educação à distância e Internet em sala de aula. In: SIMPÓSIO BRASILEIRO DE INFORMÁTICA NA EDUCAÇÃO, 1997, São José dos Campos, SP. Anais... [São José dos Campos, SP, 1997?]. p. 687-702.

2. CAMPOS, M. B.; FERREIRA, S. N. CBP 2001: uma experiência prática de sala de aula virtual nos cursos de graduação da PUCRS. In: CLAIO, 9, 1998, Buenos Aires. [Buenos Aires : s. n., 1998?].

3. BORGES, K. S.; OLIVEIRA, J. B.; POHLMANN F. O. Ensino à distância, bibliotecas digitais e os direitos autorais. In: WORKSHOP DE INFORMÁTICA NA ESCOLA, 1999, Rio de Janeiro. [Rio de Janeiro : SBC, 1999?].

4. GUIA do estudante: conceitos do ensino à distância. [S. 1.] : Universidade Aberta de Portugal, 1998. Disponível em: <http:// 193.133.111.1/erasmus/pt/guia.html>

5. LEVACOV, Marília. Bibliotecas virtuais: (r)evolução? Ciência da Informação, Brasília, v. 26, n. 2, p. 125-135, maio/ago. 1997

6. RAABE, A.; POHLMANN F. Estudo comparativo entre sistemáticas de digitalização de documentos: formatos HTML e PDF. Ciência da Informação, Brasília, v. 27, n. 3, p. 300-310, 1998.

7. POHLMANN F. O.; RAABE, A. Direito autoral no contexto de bibliotecas digitais. In: CONGRESSO INTERNACIONAL DE (TELE)INFORMÁTICA EDUCATIVA, 3., 1999, Santa Fé, Argentina. [Santa Fé, Argentina : s. n., 1999?].

8. BAEZA-YATES, R.; RIBEIRO NETO, B. Modern information retrieval. New York : ACM, 1999. 513 p.

9. GONZALEZ, M. et al. Uma experiência de controle e registro de acesso ao acervo digital do Campus Global da PUCRS. CONGRESO NACIONAL DE INFORMÁTICA EDUCATIVA, 1999, Ciudad Real, Portollano, Espanha. [Ciudad Real, Espanha,1999?]. 


\section{Informação digital no ensino presencial e no ensino a distância}

10. BORGES, K. Sistema de empréstimo de documentos digitais. 2000. Dissertação (Mestrado) - Faculdade de Informática, PUCRS. [S. 1.], 2000.

11. CUNHA, M. B. Desafios na construção de uma biblioteca digital. Brasília: Ciência da Informação, Brasília, v. 28, n. 3, p. 257-268, set./dez. 1999.

12. BARKER, P. Eletronic libraries: visions of the future. Eletronic Library, v. 44, n. 4, p. 221, ago. 1994.

13. MARCHIORI, P. Z. "Ciberteca" ou biblioteca virtual: uma perspectiva de gerenciamento de recursos de informação. Ciência da Informação, Brasília, v. 26, n.2, p.115-124, maio/ago. 1997.

14. GILHEANY, S. The next three years on the Internet for publishing and libraries : (1999 - 2002). Disponível em: < http://www.Archive Builders.com/aba014.html> Acesso em: 1999.

15. MICHEL, J. Direito de autor, direito de cópia e direito à informação. Ciência da Informação, Brasília, v. 26, n. 2, maio/ago. 1997.

16. DAVIES, D. W.; PRICE, W. L. Security for computer networks: an introduction to data security in teleprocessing and eletronics funds transfer. [S. 1.] : J. Wiley, 1984.

17. GONCALVES, M. Protecting your Web site withfFirewalls. [S. 1.] : Prentice Hall, 1997.

18. YÁBAR, José Manuel. Nuevas tecnologías y formación presencial. Disponível em: <http://roble.pntic.mec.es/atei/programa/franja3/cursos/ all_42.htm > Acesso em: ago. 1998.
19. POHLMANN F., O. et al. Em direção a criação de uma biblioteca digital na PUCRS: uma experiência prática. In: SEMINÁRIO INTERNACIONAL DE BIBLIOTECAS ASSOCIADAS A UNESCO, 2., 1998, Cienfuegos, Cuba. [S. 1. : s. n., 1998?].

20. OPPENHEIM. El derecho de autor en la era electrónica. In: INFORME MUNDIAL SOBRE LA INFORMACIÓN, 1997-1998. p. 371-383. [Paris] : Unesco, [1998?].

21. BORGES, K. S. OLIVEIRA, J. B.; POHLMANN F. O. Bibliotecas digitais: uma proposta para o controle de direitos autorais. In: INTERNATIONAL CONFERENCE ON ENGINEERING AND COMPUTER EDUCATION, 2000, São Paulo. [S. 1. : s. n., 2000?].

22. BARBIERO, E.; GONZALEZ, M.; RUIZ, D. Workflow para construção de acervo digital via Web. In: INTERNATIONAL CONFERENCE ON ENGINEERING AND COMPUTER EDUCATION, 2000, São Paulo. [S. 1. : s. n., 2000?].

23. UNIVERSIDADE NACIONAL DE ENSINO À DISTÂNCIA. Régimen académico y modelo educativo. Disponivel em: <http:// www.uned.es/regimen/ > Acesso em: set. 1998.

24. AGUIRRE, J. Sistemas educativos, sociedad e Internet. Disponivel em: < http://www.ur.mx/principal/veritas/agirre.htm> Acesso em: jul. 1998. 